\title{
TRANSFORMACIONES \\ COMUNITARIAS Y REMESAS SOCIOCULTURALES DE LOS MIGRANTES MIXTECOS POBLANOS

\author{
LILIANA RIVERA-SÁNCHEZ
}

\section{INTRODUCCIÓN}

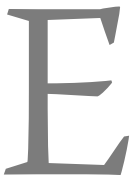

ste documento analiza algunas de las transformaciones comunitarias que han experimentado los pueblos migrantes de la mixteca poblana y cómo éstas se expresan también en Nueva York, su principal punto de destino. Hemos adoptado la imagen de la conformación de un circuito migratorio transnacional, entre la mixteca y Nueva York, a fin de entender la dinámica del espacio social de la vida migrante. Asimismo, la idea de remesas socioculturales nos permite entender, que a través de los circuitos migratorios, transita, además de personas y dinero, una serie de bienes simbólicos (música, narraciones, imágenes, experiencias, discursos, entre otros) que permiten la reconstrucción de la referencia comunitaria y del espacio social, tanto en la mixteca como en Nueva York.

El documento ofrecerá, en la primera parte, una presentación de las principales características sociodemográficas de los inmigrantes mexicanos en Nueva York. En la segunda parte, analizaremos el antes y después de los pueblos migrantes mixtecos, sus diferentes etapas de migración y los cambios ocurridos a partir del aceleramiento de la migración internacional. Asimismo, destacaremos las transformaciones comunitarias a partir de la alta movilidad del circuito migratorio. En la tercera parte, ofreceremos nociones de cómo funciona la organización comunitaria transnacional de los mixtecos poblanos y cómo las remesas socioculturales contribuyen a la conformación de las identidades migrantes.

A lo largo del texto, a través de testimonios, presentaremos las historias de los inmigrantes de la región mixteca y, en su propia voz, intentaremos comprender las transformaciones de su espacio social. En ese sentido, este documento de investigación se cimenta en el trabajo de campo realizado, tanto en la mixteca poblana como en Nueva York, a través de entrevistas a profundidad, historias de vida, observación etnográfica y grupos focales. 


\section{¿QuiÉNes SON los MeXiCANOS QUe EMIGRAN A Nueva YorK? \\ De la SiERRA MIXTECA A LA CIUDAD DE LOS RASCACIELOS}

El flujo de migrantes mexicanos a Nueva York es un fenómeno relativamente reciente, causado por una gran variedad de condiciones en los mercados de trabajo, tanto mexicano como estadounidense, pero, fundamentalmente, debido a un proceso constante de deterioro de los niveles de vida, sobre todo en las zonas rurales de México. Esta migración ocurrió más tarde que la migración mexicana tradicional hacia los estados fronterizos de Texas y California, en Estados Unidos. En 1997, siete millones de personas que residían en Estados Unidos habían nacido en el extranjero, representaban el 27\% del total de habitantes de Estados Unidos. Debido al alto número de inmigrantes «indocumentados» es difícil calcular, con precisión, la población mexicana en la ciudad y área metropolitana de Nueva York. El estimado, en el año de 1997, fue de 230 mil mexicanos en la ciudad y un adicional de 100 mil en el área metropolitana. En 1990, el estado de Nueva York tuvo el incremento más alto en el número de inmigrantes mexicanos, aproximadamente de $8 \%$, mucho más alto que en estados como California y Florida, los cuales constituían algunos de los destinos tradicionales de la migración mexicana hasta los años ochenta (González, 1999). En el año 2000 se estimó en 500 mil la población mexicana en el área metropolitana de Nueva York. ${ }^{1}$

En la última década, la población mexicana en la ciudad creció a ritmos acelerados debido no sólo a la llegada de nuevos inmigrantes, que recién cruzan la frontera, sino también a causa de, por un lado, una alta fertilidad de las familias mexicanas y, por otro, las migraciones internas (flujos originados en otros estados, por ejemplo en California, Estados Unidos). Entre 1990 y 1996 hubo 29 mil nacimientos de niños mexicanos, esto representó el 3\% del total de niños nacidos en la ciudad de Nueva York en un periodo de seis años (Department of City Planning, 1999). Solamente dominicanos y jamaiquinos sobrepasaron la tasa de nacimiento de mexicanos (Department of City Planning, 1999).

El proceso de migración mexicana a Nueva York inició en la década de los años cincuenta, ${ }^{2}$ pero su incremento más notable tuvo lugar entre finales de los setenta y, fundamentalmente, durante la primera mitad de los años ochenta. Este incremento se refleja en los datos del Censo de Población de Estados Unidos de 1990. La población de origen mexicano creció de 7,364 a 21,623 entre 1970 y 1980, y se incrementó a 61,722 en 1990 (Bada-García, 1998). Pero, sin duda, su aumento más notable podemos observarlo en el último Censo de Población (2000), donde la población mexicana fue de 187 mil (The US Population Census, 2000). En otras palabras, entre 1980 y 1990, la población creció $185 \%$ y, en la siguiente década (1990-2000), 203\%. Hoy en día, los mexicanos son el tercer grupo nacional más grande en la ciudad, después de puertorriqueños y dominicanos (The US Population Census, 2000). No obstante, sabemos que muchos de los mexicanos, que viven en Nueva York, no son contados en los censos,

${ }^{1}$ 〈www.tepeyac.org〉. El área metropolitana está constituida por la zona tri-estatal de Nueva York, Connecticut y Nueva Jersey.

${ }^{2}$ De acuerdo con Robert Smith, director de The Mexican Migration Project de Columbia University, el primer migrante mixteco poblano que viajó a Nueva York cruzó la frontera el 6 de julio de 1943. 
debido a su condición de indocumentados, esencialmente por el temor a ser descubiertos por las autoridades migratorias.

La migración mexicana hacia Estados Unidos, cuyos puntos de destino tradicional eran ciudades en los estados fronterizos de California y Texas, ha inaugurado nuevas rutas, formas de migración y establecimiento en los lugares de destino; difícilmente los migrantes llegan solos a los nuevos destinos: con antelación han establecido contactos y explorado posibilidades de empleo. Los migrantes que van a Nueva York han utilizado redes sociales previamente establecidas con personas ya residentes en la ciudad, quienes son originarios de las mismas comunidades. Pueden ser familiares cercanos, compadres, amigos o simplemente vecinos del lugar. La mayoría de ellos cruzan la frontera, ilegalmente, por Tijuana ${ }^{3}$ (esta es una de las rutas más convencionales), ciudad mexicana que hace límite con California, en Estados Unidos; pagan a un «pollero ${ }^{4}$ contratado en sus comunidades de origen, quien los enlaza con un «coyote» ${ }^{5}$ para, finalmente, llegar a su destino en alguna ciudad de Estados Unidos. El costo es de entre 1,200 y 2,000 dólares, lo cual incluye el cruce de la frontera y transporte hacia algún aeropuerto en Estados Unidos. ${ }^{6}$ El punto convencional de arribo es el aeropuerto John F. Kennedy o el de Newark, donde son esperados por sus familiares, quienes les proveen, temporalmente, alojamiento. Se estima que el 30\% de los que llegan cuenta con un empleo esperando por ellos. ${ }^{7}$ Los empleos más comunes son en restaurantes (en sus diversas categorías: desde lavaplatos, busboys, meseros, encargados del aseo, entregadores de pedidos a domicilio, hasta cocineros); vendedores de flores, frutas y verduras; empleados en tiendas de abarrotes y delis, lavanderías y tintorerías; cuidando niños, enfermos y ancianos; limpiando casas y oficinas; obreros en talleres de costura, fábricas de ropa, la construcción o en establecimientos para el lavado de automóviles.

Las causas del alto flujo migratorio pueden encontrarse tanto en Nueva York como en La Mixteca Sur, ${ }^{8}$ región de donde ha emigrado el mayor número de mexicanos que viven en Nueva York. Particularmente estos migrantes son orginarios de zonas rurales e indígenas, de municipios como Izúcar de Matamoros, Piaxtla, Chinantla, Tulcingo de Valle, Acatlán de Osorio, Tecomatlán, Tehuitzingo en Puebla, o de la región

\footnotetext{
${ }^{3}$ Otros puntos de cruce han sido inaugurados debido a la militarización de la frontera en ambos lados. Algunos de ellos cruzan por Phoenix, Arizona, aunque también lo han hecho, recientemente, por Tamaulipas, en su frontera con Brownsville, Texas.

${ }^{4}$ Son las personas que en sus comunidades de origen se dedican a juntar a los migrantes y entregarlos a los coyotes. Los polleros hacen enlaces, muchas veces, desde el sur y sureste del país hasta la frontera con Estados Unidos y su contrato puede garantizar la llegada hacia ciudades en el norte de dicho país, o bien, exclusivamente el cruce de la frontera. Esto es posible gracias a redes de contacto en diversas ciudades estadounidenses.

${ }^{5}$ Es el nombre que reciben las personas que se dedican a pasar ilegalmente a los migrantes en la frontera entre Estados Unidos y México. El transporte del paso en la frontera es terrestre, pero después puede incluir algún vuelo interno, tren o autobús.

${ }^{6}$ Información proporcionada por Asociación Tepeyac de Nueva York, bajo el testimonio de inmigrantes mexicanos.

${ }^{7}$ Este dato corresponde a información anterior al 11 de septiembre de 2001.

${ }^{8}$ La Mixteca Sur es una región en la parte central-sur de México que comparten tres estados del país: Puebla, Guerrero y Oaxaca. Se trata de una región eminentemente rural e indígena, dedicada a actividades agrícolas de temporal, fundamentalmente el cultivo de maíz, frijol, calabaza y sandía, así como a la cría de ganado caprino.
} 
aledaña a Huajuapan de León, en Oaxaca; la zona de Tlapa y la montaña de Guerrero, entre muchos otros de dicha región; indudablemente, también del Valle de Atlixco, en Puebla. Algunos son de segunda migración y proceden desde Ciudad Nezahualcóyotl y Valle de Chalco, en el Estado de México. La región de la Mixteca fue una de las zonas que sufrió, mayormente, los efectos de la crisis económica mexicana de la década de los ochenta, efectos que se intensificaron con algunas políticas de liberalización en el campo mexicano y acuerdos comerciales que iniciaron desde $1986,{ }^{9}$ mismos que culminaron con el Tratado de Libre Comercio de América del Norte, entre Estados Unidos, Canadá y México, en 1994. Más recientemente, la crisis financiera de 1994 se presume que repercutió en los altos flujos de migrantes que salieron de la región (Binford y D’Aubeterre, 1999). Hoy en día, los principales puntos expulsores de migrantes mexicanos hacia Estados Unidos son Jalisco, Michoacán, Zacatecas, Oaxaca, Guerrero, Puebla, Tlaxcala, Morelos, Estado de México y Distrito Federal.

El mercado de trabajo en Nueva York ha mostrado una demanda creciente de fuerza de trabajo no calificada. Esos lugares han sido ocupados, fundamentalmente, por inmigrantes. Entre 1980 y 1990, los trabajadores inmigrantes aumentaron su participación en el mercado de la zona metropolitana y pasaron de 22 a 33\%, respecto del total. De acuerdo al grupo étnico, los trabajadores hispanos nacidos fuera de Estados Unidos se incrementaron del 6 al 11\%. Así, en el contexto de mercados de trabajo con requerimiento de mano de obra no calificada, la población inmigrante joven encuentra un nicho atractivo. El 60\% del total de la migración mexicana, desde el estado de Puebla hacia Nueva York, se encuentra entre las edades de 15 y 24 años (INEGI, 2000). La mayoría de estos inmigrantes tienen, como grado máximo de escolaridad, la educación secundaria (el equivalente al noveno grado en Estados Unidos). En 1995, 25.9\% del total de la población de la región mixteca no sabía leer ni escribir, lo cual representa uno de los índices más altos de analfabetismo en el país, dado que el promedio nacional es de 9.5\% (INEGI, 2000).

El estado de Puebla cuenta con una larga tradición migratoria. En 2000, el 7\% de poblanos, residentes en el estado, habían vivido fuera de sus municipios de origen. De estos poblanos con experiencia migratoria, el $41 \%$ había tenido, al menos, un periodo de residencia en Estados Unidos y el resto en alguna otra ciudad de México. De éstos, el más alto índice fue registrado en la región sur de Puebla, donde el 57\% había residido, al menos un periodo de su vida, en Estados Unidos, mientras que un 43\% lo había hecho en cualquier otra ciudad del país. Atendiendo a diferencias de género, 38 de cada 100 migrantes poblanos son mujeres y 62 son hombres. En términos de sus puntos de destino, observamos que el $80 \%$ de las mujeres migrantes ha vivido o vive en una localidad diferente a la de su lugar de origen; el 20\% restante ha vivido en Estados Unidos al menos un periodo de su vida. Mientras, en el caso de los hombres migrantes, tenemos que $64 \%$ han vivido en alguna otra localidad mexicana y $36 \%$ lo ha hecho en Estados Unidos (Cortés, 2002).

Por otro lado, la saludable economía de la ciudad de Nueva York y, en general, de Estados Unidos, antes de finales de 2001, fue un incentivo para que los mexicanos se aventuraran en la búsqueda de mejores condiciones de vida, con la certeza de que los mercados de trabajo en Estados Unidos requieren de su fuerza laboral para seguir

\footnotetext{
${ }^{9}$ Estamos refiriéndonos fundamentalmente a la entrada de México al GATt, en 1986.
} 
produciendo. Adicionalmente, algunos programas de amnistía para trabajadores indocumentados han sido importantes recursos para la reunificación familiar, particularmente la iniciativa de 1986, que concedió estatus legal a los indocumentados con al menos diez años de permanencia en Estados Unidos; más tarde, la Ley de Inmigración de 1990 otorgó la «legalización de los dependientes» o familiares de quienes consiguieron estatus legal en 1986. De esta manera, algunos mexicanos en el área de Nueva York consiguieron legalizar su situación, pero la gran mayoría, inmigrantes llegados en la última década, permanecen en la categoría de «trabajadores indocumentados» y sufren las consecuencias en el mercado de trabajo. Además de sufrir de discriminación en los diferentes espacios donde se socializan, sus derechos más básicos son violados por los patrones, con jornadas excesivas de trabajo, falta de prestaciones sociales y salarios por debajo de los mínimos establecidos por la ley, siempre bajo la amenaza de ser denunciados a las autoridades migratorias.

En este contexto, la construcción de espacios de encuentro comunitario se ha convertido, también, en un importante referente para estos inmigrantes mexicanos en la sociedad neoyorkina, donde el espacio para la construcción de nuevos barrios étnicos se encuentra en disputa. Los mexicanos, como inmigrantes de más reciente arribo en esa ciudad, han tenido que compartir el espacio urbano, fundamentalmente, con puertorriqueños y afroamericanos en el Bronx; con ecuatorianos, colombianos, centroamericanos y otros latinos en Queens, donde también han compartido espacios, en este condado, con asiáticos. En Manhattan, particularmente en el lado este del Harlem, han compartido espacios con dominicanos y puertorriqueños. De tal forma que la afirmación de su identidad étnica se ha convertido en un recurso organizativo y de supervivencia cotidiana en los barrios, donde a diferencia de Chicago o Los Ángeles, no existe el barrio mexicano como tal. Esta última característica, de cómo se han asentado los mexicanos en la ciudad de Nueva York, otorga mayor relevancia a los análisis de cómo la comunidad mexicana ha construido espacios de identificación comunitaria y socioterritorial en estas condiciones.

\title{
De la mixteca poblana a Nueva York: NUEVOS DESTINOS Y TRANSFORMACIONES COMUNITARIAS
}

\author{
FISONOMÍAS, \\ PAISAJES Y RUTAS
}

En la región mixteca poblana, el fenómeno migratorio presenta tres diferentes etapas: la primera de ellas consiste en una migración regional en busca de empleos temporales y se refiere, fundamentalmente, a desplazamientos hacia algunos centros de atracción de mano de obra, tales como el ingenio azucarero de Atencingo, cercano a la puerta de la mixteca poblana, a la altura del municipio de Izúcar de Matamoros. Este ingenio constituyó, durante varios años, una importante fuente de empleo regional. Otros centros de atracción de mano de obra fueron otros ingenios azucareros, los campos citrícolas y las fincas de plátano y café en el estado de Veracruz. Todos éstos constituían empleos temporales para la población flotante de la mixteca, quienes estaban ausentes de sus comunidades, al menos seis meses del año. No obstante, la mayoría de estos trabajadores temporales mantenía sólidos vínculos con su comunidad de origen. La familia del tra- 
bajador permanecía asentada en la comunidad, muchas veces sólo el hijo mayor, o bien la esposa, acompañaban a aquél en su desplazamiento. La mano de obra femenina era un recurso valioso, ya que como cortadores de café, por ejemplo, preferían el trabajo de las mujeres sobre la mano de obra masculina. Otro vínculo, sin duda importante hacia la comunidad, lo fue la presencia de la familia extensa, así como la tenencia de la tierra y el cultivo de la misma, generalmente la siembra de maíz, frijol, calabaza y sandía; junto con la cría de ganado caprino y ovino dominaron los campos de la mixteca.

Los primeros inmigrantes [a Estados Unidos] nos fuimos cuando los braceros, por contratación, eso nos dio la idea de que podíamos ir con más facilidad. Antes de mí, si acaso habrán ido sólo unos ocho o diez de esta región. Fuimos a la ciudad de México y allí estaba la oficina de Braceros. Estaban las peticiones de los patrones de allá. En esa época pedían 100, 200 y hasta 300 y allí todos los que llegábamos nos repartían entre las peticiones de esos patrones. Todos en trabajos de agricultura [...] Fue hasta 1962 cuando dijeron que ya no había más contrataciones, sólo los que ya estábamos. En el campo donde yo estuve llegamos a ser hasta 800, todos éramos mexicanos y muchos de la región de Puebla, también de Guanajuato y Zacatecas, algunos eran de Jalisco. Esto fue en California y de ésos, sólo como 40 conseguimos la residencia [...] sólo tardaron dos meses en darla [...] Así que desde 1961 yo ya tenía papeles para vivir por allá sin sufrir más. Allí había estado yo por 13 años, trabajando, sobre todo pizcando y cortando casi de todo lo que puede uno imaginarse en el campo (don Juan, marzo de 2002).

La diferencia de la actual migración con la primera que hubo en la mixteca es que solamente se iban los jefes de familia y a veces las mujeres, pero no los jóvenes, éstos se quedaban a cuidar las tierras y los animales [...] Descubrí que Chila de la Sal y Tulcingo de Valle habían sido siempre tierra de migrantes [...] En tiempo de secas, porque allí el trabajo de campo es de temporal, ellos migraban hacia la montaña de Guerero o la montaña de Oaxaca. ${ }^{10}$ El queso que hacían aquí en tiempo de aguas, lo llevaban a cambiar por piñas, luego las piñas se las traían y las llevan a la región de Cholula, donde comerciaban también con estas piñas. Podemos decir que todos esos pueblos de la mixteca fueron seminómadas y comerciantes. Cuando terminaba ese trabajo se iban también a la zafra, especialmente a los ingenios de Veracruz. Estaban fuera de sus pueblos buena parte del año y luego regresaban a realizar sus labores de labriego (Padre Marcos, agosto de 2002).

Los migrantes temporales regresaban anualmente a sus comunidades para sembrar sus tierras y más tarde para cosecharlas. No obstante que la región mixteca es muy árida, la actividad del campo constituía una de las más dinámicas hasta los años cincuenta, aun cuando siempre el comercio fue una actividad importante en la región. La comercialización de productos desde algunas regiones de Oaxaca, tales como la región aledaña a Huajuapan de León (en la mixteca oaxaqueña), constituyó una importante fuente de ingresos en la región. El comercio de productos lácteos (queso, mantequilla y crema), productos de jarcería, así como el trabajo de curtido de pieles y

${ }^{10}$ Guerrero y Oaxaca son estados vecinos de Puebla. 
talabartería permitieron la supervivencia de muchos pueblos de la mixteca, particularmente del municipio de Tulcingo de Valle, quienes se convirtieron de campesinos a comerciantes en un corto periodo.

Ya desde aquellos años la gente empezó a abandonar sus tierras, pues no sacaba uno más que para ir comiendo. Mis hijos también se fueron para el otro lado [a Estados Unidos], y me mandan algún dinerito de vez en cuando. Yo sigo siendo agricultor, soy un campesino, pero en este pueblo, después de tantos haberlo sido, ahora sólo quedamos como 40 personas en las listas del Procampo, donde estamos todos los que cultivamos aquí. Es triste como ahora nadie sabe trabajar en la tierra, ni agarrar un azadón y tenerle el amor a la cosecha. Ahora los ricos son los que tienen tiendas, los que comercian con materiales [de construcción], que pusieron una tienda y traen productos de cualquier otro lado. A mí me pone triste como la juventud y aun los de mi edad, han dejado para siempre la tierra [...] y se volvieron comerciantes, algunos se fueron de mojados y los que regresan sólo regresan a comerciar, no a trabajar la tierra (don Rafael, abril de 2002).

Una segunda fase de migración puede ubicarse durante los años sesenta, teniendo como destino principal algunos centros urbanos, tales como la ciudad de Puebla, el puerto de Veracruz, la ciudad de México y otras áreas de la zona conurbada del Distrito Federal. Muchos mixtecos migraron hacia los alrededores de la ciudad de México; puntos importantes de atracción fueron Ciudad Nezahualcóyotl, el Valle de Chalco y Ecatepec, Estado de México, en ese momento en proceso de conurbación.

Mientras en la primera fase de migración continuaban siendo trabajadores rurales, dedicados fundamentalmente al corte de caña de azúcar, café y cítricos, así como algunos otros cultivos, en la siguiente etapa se incorporaron al trabajo urbano en la industria tabacalera, en la portuaria y de materiales de construcción, como es el caso de la migración ocurrida hacia la zona industrial del puerto de Veracruz y las fábricas aledañas a la ciudad de México. En la ciudad de Puebla se dedicaron, sobre todo, a realizar trabajo manual no industrial; muchos se incorporaron al sector de servicios, como empleados de tiendas y almacenes, oficinistas; también al trabajo doméstico, la albañilería y el ambulantaje, entre otras actividades. Algunos también consiguieron insertarse en la industria automotriz y la maquila poblana, más tarde algunos de ellos consiguieron también profesionalizarse.

A diferencia de la primera fase de migración, la segunda implicó un cambio de residencia permanente. Los primeros tuvieron la oportunidad de ser migrantes temporales, mientras que los segundos tuvieron que cambiar definitivamente de residencia. A pesar de tal hecho, muchos de ellos mantuvieron vínculos con sus comunidades de origen a través de las celebraciones locales de los santos patrones o los compromisos del parentesco, como los compadrazgos y la presencia de la familia extensa en las localidades. Este vínculo fue posible, también, porque algunos decidieron mantener pequeños predios en las comunidades mixtecas, siempre con la idea de volver a establecerse algún día en aquellas tierras.

La tercera fase se superpone a la segunda y quizá, en algún momento, también a la primera fase de migración mixteca. Esta fase implica un desplazamiento asimismo considerado temporal, pero que se prolonga hacia regiones del norte del país y hacia Estados Unidos. Dos puntos principales constituyen los lugares de destino para 
estos migrantes: el primero es California, fundamentalmente en Valle de San Joaquín y puntos urbanos como Los Ángeles y su zona conurbada, además de otras ciudades como Sacramento, Pasadena, Santa Cruz, San José y algunas ciudades fronterizas mexicanas, como Tijuana, Baja California. El segundo punto de destino, y quizá el más importante por su concentración, es la ciudad de Nueva York, a lo largo de sus cinco condados (Manhattan, Brooklyn, Queens, Bronx y Staten Island), pero también en otras ciudades de la zona conurbada como New Jersey, Connecticut y el norte del estado de Nueva York y la región de Filadelfia.

En estos destinos encontramos migrantes que directamente han salido desde las comunidades de la mixteca, es decir, son primera generación migrante, pero también hallamos un importante número de migrantes de segunda fase, esto es, aquellos que han vivido un periodo en la zona conurbada de la ciudad de México, particularmente en Ciudad Nezahualcóyotl y Ecatepec, en el Estado de México, en la ciudad de Puebla o, bien, que han trabajado algún periodo en California, antes de migrar a Nueva York. Es decir, algunos de los migrantes mixtecos pasan, de manera directa, de desempeñar trabajo rural a realizar trabajo urbano en Nueva York.

Y después de trabajar tanto en los campos de California, por más de 13 años, decidí irme a Nueva York, yo pensaba antes que allá sólo iban los flojos, pues allá se trabaja por hora y no por jornal, como en el campo. Estuve en una fábrica por más de 22 años hasta el día en que me jubilé [...] Para mí el trabajo en la fábrica es aburrido, prefiero el campo, pero como fui a vivir a Nueva York, más concretamente me pasé a New Jersey, tenía que trabajar en fábrica y así lo hice [don Juan, marzo de 2002).

El cambio de actividad, radicalmente distinto, ha impreso también un nuevo sentido a la migración transnacional, lo cual implica no sólo un cambio de residencia, sino de un modo de vida: del campo a las grandes urbes, además de una transformación de la identidad, que va de la basada en la presencia de la familia extensa a la individualidad del trabajo urbano desde la habitación en un departamento y la lejanía de sus referentes comunitarios, además de su lengua; aún cuando la mayoría de estos migrantes se mueven en red, experimentan, en los primeros momentos del desplazamiento, ciertos sentimientos de soledad, anonimato y distensión de los lazos familiares. Estas emociones no eran muy claras en las primeras dos fases de migración, pues la posibilidad de regresar al lugar de origen se observaba más cercana. Aún más, algunos migrantes mixtecos han manifestado recurrentemente en sus testimonios que experimentan, en el caso de los hombres, también cierta erosión de su «sentido de masculinidad», pues tienen que insertarse en el mercado de trabajo ocupando los lugares disponibles, habitualmente empleos que en su lugar de origen, y en general en México, ellos no hubieran tomado: se trata de lavar platos, cocinar, trabajo de limpieza en cocinas y baños, en fin, actividades que, desde cierta perspectiva local, eran consideradas de competencia femenina. Al respecto, comenta don Neftalí:

[...] y aquí ni pensarlo, yo en mi casa no cargo ni un balde de agua, pues no me vaya a lastimar la espalda, eso lo hace mi mujer [...] Pero allá, en Nueva York, yo fui a trabajar primero lavando platos, era una fila interminable de platos sucios, en la cadena había unas ollas que ni se imaginan, tenían mi tamaño y había casi 
que meterse en ellas para lavarlas [...] no lo vuelvo hacer, pero allá se pagaba en dólares y eso lo hacía distinto [...] luego fui cajero y la cosa cambió, pero también limpié algunos pisos y eso [...] aquí nunca lo haría, pero allá es en dólares y hasta el orgullo se pierde (don Neftalí, abril de 2002).

Las diferentes fases de migración mixteca han impreso transformaciones diferenciadas en el paisaje de los pueblos migrantes, pero indudablemente que una de las transformaciones más visibles de esta región se experimenta a partir de la migración transnacional, misma que se ha visto acelerada durante las últimas dos décadas. En el siguiente apartado veremos cómo se observa el paisaje sociocultural en los pueblos migrantes y cómo el movimiento constante de bienes simbólicos, personas y dinero ha generado transformaciones comunitarias, tanto en la mixteca como en Nueva York.

\section{TRANSFORMACIONES}

SOCIOCULTURALES DEL ESPACIO SOCIAL

En las narrativas de los migrantes encontramos que el desplazamiento a edad temprana se ha convertido en un ritual en la vida de los jóvenes mixtecos, después de la secundaria, en el caso de los hombres o después de la preparatoria, recientemente en el caso de las mujeres. Ellos visualizan, en su imaginario, a la migración hacia Estados Unidos como el siguiente paso en su vida. Las familias de los migrantes argumentan que las razones del desplazamiento siguen siendo, fundamentalmente, económicas, es decir, la imposibilidad de conseguir un empleo, que les permita sustentar sus necesidades y las de sus familias, se convierte en razón suficiente para migrar al norte, donde muy probablemente ya tienen un referente, el cual puede ser algún vecino, un amigo o un familiar. También migran los profesionistas: encontramos interesantes experiencias de profesores, ingenieros, trabajadores sociales, médicos y otros profesionistas que, también, narran cómo decidieron dejar algunos empleos y vivir la experiencia de la migración, al fin y al cabo resultaba más atractiva en términos económicos.

A pesar de todo, y de que todos van a Nueva York, la migración sigue teniendo motivos económicos. Uno ve a los estudiantes de secundaria ya apresurados por terminar sus cursos, pues el siguiente paso es irse a Nueva York, ya no les interesa seguir estudiando, pues ven que aquí no tienen futuro. Uno ve en la preparatoria que casi el $80 \%$ de los estudiantes son mujeres, ellos ya se fueron (profesor, abril de 2002).

Fui un inmigrante por algunos años, indocumentado como muchos, trabajé en un restaurante en Nueva York [...] Yo veía cómo todos se iban y regresaban con dinero, quise probar también. Luego volví, no hice realmente mucho dinero [...] Conozco muchas historias, de gente vendiendo flores en Nueva York, por ejemplo, en plena Quinta Avenida y son ingenieros, hicieron una carrera universitaria y se recibieron, no encontraron trabajo en lo suyo y se fueron a Nueva York. Paradójicamente, cualquiera gana más allá que aquí en el pueblo o en la región, con algún título. Nuestros jóvenes así no tienen muchas ganas de superarse, eso nos preocupa en el pueblo (profesor migrante, abril de 2002). 
La fisonomía de los pueblos migrantes se ha transformado en términos poblacionales: en la mixteca encontramos un sinnúmero de pueblos deshabitados, donde la población mayoritaria son hombres y mujeres de la tercera edad. Algunos fenómenos significativos han tenido lugar, tales como el cierre de un jardín de niños y una escuela primaria, localizados en la carretera principal hacia la mixteca profunda, lo cual es altamente representativo de la ausencia de menores y jóvenes. Comenta un profesor de Tulcingo de Valle:

Aquí donde pasa la carretera, nos acaban de cerrar unas escuelas que costaron muchos años para que fueran abiertas; cuando se logró que hubiera escuelas, ya que se pidieron porque los niños las necesitaban y se llenaban los cupos requeridos, sólo a los dos años bajó tanto la matrícula que tuvieron que ser cerradas. ¡Ya no había niños!, quedaron muy poquitos, nosotros como profesores estábamos muy preocupados con ese hecho [...] ahora están allí, sin usarse esas instalaciones [...] Eso es lo que está pasando con nuestros niños (profesor, mayo de 2002).

Indudablemente, las transformaciones más visibles aluden al estilo de las nuevas casas y negocios, así como de las empresas que ahora se dedican a construirlas: «se construyen casas estilo Nueva York», anuncian. Muchos migrantes envían dinero a su familia para construir una casa que nunca será habitada, pues muchos de ellos ya no regresarán a vivir al pueblo. Es notable observar grandes casas deshabitadas.

La proliferación de antenas parabólicas, casas de cambio, establecimientos para el envío y recepción de dinero y paquetería, de venta de comida griega, china, italiana y «hamburguesas estilo Nueva York» son parte del escenario de los pueblos de la mixteca poblana. Estos cambios han modificado, también, los patrones alimenticios de la región: casi en cualquier comunidad mixteca encontramos negocios de hamburguesas, hot dogs, pizzas y otros. La presencia, asimismo, de cafés internet, venta de computadoras y electrónicos no es ajena al panorama. Algunos de estos pueblos, como Tulcingo de Valle, cuentan ya con una página de internet que les permite comunicarse con los familiares y amigos que están en Estados Unidos, así como compartir las celebraciones locales vía electrónica.

En el afán de «modernizar» las construcciones, ha terminado con algunas pocas casas de tejamanil y adobe, que aún se conservaban en el centro de los viejos poblados. Las lajas del atrio de la iglesia de Tulcingo de Valle, las cuales tenían más de un siglo con inscripciones originales, han sido cambiadas por adoquín financiado por los migrantes de Nueva York, quienes han preferido «poner bonita y moderna la iglesia de San Gabriel». De la misma forma, las celebraciones comunitarias han sufrido modificaciones, pues la tradición era que las fiestas familiares, como bodas, quinceañeras y bautizos, fueran amenizadas con música de banda; ahora se escucha la presencia de grupos norteños, bachata dominicana, cumbia y vallenato colombianos, junto con algunos sonidos puertorriqueños, como parte de los efectos de la globalización musical pero, indudablemente, también de la influencia de los inmigrantes de Nueva York.

Algunos de los mayordomos de las fiestas de los santos patrones locales vienen de Nueva York o de otras ciudades de Estados Unidos, pues son ellos quienes cuentan con los recursos suficientes para financiar los gastos de las grandes fiestas patronales en las localidades mixtecas. Y nos comenta un sacerdote que trabajó durante 20 años en la región: 
Las fiestas de nuestros santos han cambiado mucho. Algunas son un derroche de dinero, y no tienen ya nada que ver con la religiosidad de antes. Han desaparecido algunos criterios de moralidad para elegir a los mayordomos de fiestas. Ahora son grandes bailes, y disturbios, sonidos en grandes altavoces y bueno, corre mucho alcohol y también drogas, es impresionante como corre la droga ahora en las fiestas. Luego vienen los problemas de salud, eso del sida está ya presente en nuestras comunidades, antes ni pensarlo. Las bodas y los bautizos son difíciles para nosotros, nos hablan desde Nueva York y quieren saltarse las pláticas prenupciales y las de los padrinos, sólo porque te pueden pagar en dólares la celebración de las misas, luego te ponen en el dilema de si no se las haces, pues de todas maneras se llevarán a la novia o no bautizarán al hijo [...] claro que no todos, pero ya tenemos muchos casos así (sacerdote, agosto de 2002).

Las transformaciones de la vida migrante no sólo se experimentan en el paisaje y las celebraciones. De igual forma, en la vida cotidiana de las familias, los roles tradicionales han sufrido modificaciones: ahora no sólo emigran los hombres, sino también las mujeres jóvenes; muchos emigran en pareja, de tal suerte que experimentan, en menor medida, la experiencia de la familia escindida por la ausencia del padre-migrante. Sin duda, aún encontramos muchos casos de familias escindidas en la mixteca, pero la experiencia reciente muestra que el tiempo de migración de la pareja se ha reducido, es decir, ahora únicamente esperan algunos meses para llevarse a su mujer e hijos, incluso en la condición de indocumentados o, cuando no existen los hijos, emigra la pareja desde el primer viaje. Esto ha generado una relación distinta entre hombres y mujeres, así como el consecuente desarrollo de roles. Las mujeres jóvenes ocupan empleos, en el nuevo destino, y adquieren una actitud no tradicional respecto de su papel como madre de familia y esposa. Estos cambios relacionales, al interior de la familia, han provocado modificaciones en las estructuras comunitarias: algunos vínculos del parentesco parecen relajarse, aun cuando son reafirmados en el momento en el que regresan (aunque temporalmente) a las comunidades de origen. Comenta un padre de familia lo que experimenta en relación a sus hijos, todos ellos inmigrantes radicados en Nueva York:

Los viejos hemos perdido toda autoridad con la familia, antes nuestro consejo era escuchado, y sobre todo las mujeres nos obedecían, ahora ni mi mujer y mucho menos mis hijas, tampoco los hijos varones, pues desde que se fueron a Nueva York mandan dinero y eso les da fuerza para mandar. También el pueblo escuchaba la opinión de los más viejos y tomaba los consejos, ni las autoridades ahora se interesan (don José, julio de 2002).

Este cambio en el rol de las mujeres, ahora también migrantes, ha provocado un proceso de empoderamiento de las mujeres mixtecas poblanas. Si bien no se trata de un fenómeno generalizado, existen mujeres empresarias y profesionales que transitan, del mismo modo, en el circuito migratorio y son actores protagónicos de éste. Encontramos también mujeres como algunos de los mejores coyotes, especializadas en el tránsito de personas de la región mixteca. Algunas de las mujeres se han convertido en dirigentes de incipientes grupos de oriundos en Nueva York, quienes se organizan alrededor de la iglesia católica, pero cuyas actividades trascienden el ámbito propia- 
mente religioso, al grado de ser, algunas de ellas, interlocutores en organizaciones de defensa de derechos humanos en Estados Unidos, como en el caso de dirigentes de grupos barriales de la Asociación Tepeyac, en Nueva York.

Una mujer migrante, que hacía una estancia vacacional en Tulcingo de Valle, nos permite ilustrar el proceso de capitalización de las mujeres en la región mixteca:

Yo decidí irme un día y me convertí en la primera mujer que migraba a Nueva York desde esta región, bueno, de Tulcingo. En ese entonces iban sólo los hombres y yo quise hacerlo también, pues quería ayudar a mi mamá [...] Me fui en 1970 y aquello era aún más difícil, aun cuando fui con una ahijada, nadie creía en nosotros, menos siendo mujeres [...] Pero he trabajado por muchos años como empleada de una joyería, ahora voy y vengo cuando yo quiero. Tengo papeles y creo que puedo hacerlo. En el barrio donde vivo en Nueva York, en el Bronx, también le ayudo a los otros, les cuento mi historia y ahora tengo muchos ahijados, así los llamo aunque no lo son, pues son muchachos que estaban solos y que los he orientado [...] Todos tenemos derecho a una vida mejor y si nuestro país no la puede dar, hay que ir a buscarla (Gris, abril de 2002).

El capital simbólico acumulado por estas mujeres y, en general, por jóvenes migrantes, se ha multiplicado por su experiencia migratoria pero, fundamentalmente, como resultado del proceso de aprendizaje colectivo derivado del hecho de enfrentarse a nuevas condiciones en el mercado de trabajo, a una sociedad a la que han llegado a insertarse sin conocer el idioma, culturalmente distinta y enriquecida, constantemente, por el repertorio cultural de muy diversos grupos nacionales.

\section{TRANSFORMACIONES E INTERCAMBIO} SIMBÓLICO: LAS REMESAS

Las transformaciones comunitarias en las sociedades de origen no devienen, necesariamente, del envío de dinero, sino también de las remesas socioculturales que cotidianamente reciben y envían. La música, las festividades, las tradiciones, la comida, los nuevos retos y experiencias organizativas, el ir y venir constante de imágenes y narraciones posibilitan la reconstrucción de la referencia comunitaria en los puntos de destino, pero también recrean la identidad no sólo del inmigrante, sino de quienes permanecen de este lado de la frontera. Los repertorios culturales no conocen barreras: la posibilidad de que las remesas socioculturales circulen a través del circuito migratorio depende de la intensidad de los flujos y de la vinculación de los inmigrantes hacia sus comunidades de origen. Indudablemente, la supervivencia de muchos de los pueblos de la mixteca poblana depende, en gran medida, de las remesas económicas, pero las remesas socioculturales son las que posibilitan el dinamismo del circuito migratorio. Diariamente, las casas de cambio y envío de paquetería y dinero se encuentran saturadas por mujeres, ancianos y jóvenes que esperan recibir el dinero para los gastos de la semana, para resolver una emergencia médica o para continuar la construcción de su casa o negocio. Estas mismas agencias de paquetería y dinero se encuentran, asimismo, siempre dispuestas a embalar los paquetes que, desde la mixteca, envían a sus familias en los Estados Unidos; entre éstos encontramos un sinnúmero de artículos y productos no autorizados para 
su transporte al vecino país del norte, los cuales son enviados, diariamente, a través de servicios locales de paquetería - Delgado Travel, Tulcingo-New York Express y Tulcingo Travel son algunos de los más conocidos en la región-. Los envíos contienen salsas caseras, conservas de ciruela y otras frutas; semillas de guaje, capulines, hojas de hierba santa; estampas de santos y vírgenes locales, escapularios, velas y agua bendita; pan recién horneado, pipianes y moles caseros; quesos frescos; carne preparada. Al respecto, doña Ana comenta sobre su más reciente envío:

En Navidad tenía mucha desazón porque todos mis hijos están en Nueva York y no estarían este año con nosotros, algunos tienen papeles y otros no los tienen y se ha vuelto peligroso estar viniendo. Le dije a mi marido, les voy a cocinar lo que más les gusta y se los envío ya al punto para que allá lo calienten. Les preparé un chivito con todos sus condimentos y recaudos, un chivo bien preparado en barbacoa de hoyo [...] El 23 de diciembre en la madrugada salió listo y se los mandé [...] en uno de esos trastes grandes donde no se escurre y llega buenesito [...] Tardaron dos días en entregarlo porque el que hace los envíos se olvidó de ese traste que puso en su cajuela del carro, pero como en Nueva York estaba nevando, pues ni se echó a perder. Mis hijos se lo comieron al otro día y me hablaron para decirme que estaba muy bueno. Una se siente contenta cuando lo que se hace aquí se quiere mucho allá (doña Ana, febrero de 2003).

Las imágenes, narraciones, discursos y bienes en general, transportados desde la mixteca hacia Nueva York, pero también desde Nueva York hacia la mixteca, contribuyen al fortalecimiento del circuito migratorio, luego a la intensidad de los flujos, pero, fundamentalmente, al reforzamiento de los lazos comunitarios y la identidad de los inmigrantes, incluso en su condición de desplazamiento. Asimismo, además del dinero, los inmigrantes en Nueva York envían a sus comunidades de origen una serie de bienes, imágenes, narraciones (ya sea a través de música, fotografía, historias, vivencias personales y bienes materiales en general) que se convierten, también, en remesas socioculturales para estas comunidades, permitiéndoles ampliar los horizontes y concepciones de su entorno social.

Esta dinámica del circuito migratorio transnacional implica un intercambio simbólico de alta movilidad y, de igual forma, posibilita la ampliación de la concepción de comunidad, en una imagen de comunidad transnacional sin límites geográficos ni barreras culturales (Rouse, 1996). En el siguiente apartado observaremos cómo estas remesas socioculturales se fortalecen a través de la organización comunitaria transnacional de los mixtecos poblanos en Nueva York.

\section{ORGANIZACIÓN COMUNITARIA TRANSNACIONAL Y REMESAS SOCIOCULTURALES}

\section{Patrones de Migración y NUEVAS FORMAS DE ESTABLECIMIENTO}

Las teorías contemporáneas de migración internacional nos dan nuevas pistas para entender las formas de establecimiento e incorporación de las nuevas comunidades 
inmigrantes en Estados Unidos, al analizar de manera diferente el curso de la migración a cada sitio y la importancia de las formas de establecimiento en las sociedades de destino, más allá de las estrategias circulares recurrentes de los migrantes, sobre todo de los migrantes mexicanos. Podemos observar que, en el caso de los mixtecos poblanos, la migración se convierte en un ritual de paso para las nuevas generaciones de inmigrantes, quienes se desplazan como parte de los rituales de vida. Como resultado, la migración transnacional se convierte en un proceso que se autorefuerza y que, cada vez, es más independiente de la condición que originalmente la causó (Massey et al., 1994). Estas posiciones teóricas coinciden, también, en que la acumulación de capital social, producido por los constantes movimientos hacia Estados Unidos y sus comunidades de origen, reduce los riesgos y los costos de la migración y, así, eliminan la selectividad de este proceso, convirtiéndose en un desplazamiento prácticamente local y cotidiano. Don Sebastián nos permite ilustrar cómo se perciben los desplazamientos a Nueva York desde los pueblos de la mixteca:

Para nosotros ir a Nueva York es casi como ir aquí a Tecomatlán, Tehuitzingo, o Acatlán [son los pueblos vecinos], o bien casi como ir a Puebla, que está un poco más lejos para nosotros. Pero aquí todos han ido a Nueva York. Allí donde ve cualquier muchacho que aquí camina por la banqueta, o los que trabajan en la tienda, van, hacen un dinerito y se regresan, luego vuelven a ir (don Sebastián, abril de 2002).

De esta manera, el proceso de acumulación de capital social (como experiencia, contactos, conocimiento sobre los mercados de trabajo, los «coyotes» y los pasos apropiados en la frontera, por ejemplo) produce, con el tiempo y en las diversas comunidades, la conformación de nuevas estrategias de desplazamiento, seguido de otros patrones migratorios. En el caso de la mixteca, nosotros observamos que estos nuevos patrones migratorios, fincados en redes de parentesco y una constante movilidad circular, representan también nuevas formas de incorporación y establecimiento en la ciudad de Nueva York, lo cual no necesariamente implica aculturación, ni asimilación en la sociedad de destino, sino una especie de alargamiento socioespacial de las referencias simbólicas comunitarias, independientemente de las fronteras geográficas (Rouse, 1996).

Estos nuevos patrones migratorios están basados en movimientos constantes de personas, dinero, bienes, información, imágenes; en términos generales se trataba de la circulación de bienes simbólicos. La vinculación recurrente de los migrantes hacia las comunidades de origen les permite recrear un vecindario étnico, un barrio particular, es decir, nuevas formas de apropiación sociocultural del espacio urbano, ya sea mediante organizaciones con referencia local, por ejemplo, un equipo de futbol soccer cuyos miembros son de un mismo pueblo de origen o un comité Guadalupano afiliado a la Asociación Tepeyac, que tiene correspondencia con habitantes de una misma comunidad en la mixteca poblana. No obstante, todas estas formas de establecimiento y organización comunitaria, en la ciudad de Nueva York, aparecen como transitorias en el imaginario de los inmigrantes, en virtud de la promesa de que pronto regresarán a sus lugares de origen. La transitoriedad del establecimiento es un argumento típico de los inmigrantes mixtecos en esa ciudad (muy probablemente de muchos inmigrantes mexicanos en Estados Unidos) y constituye una importante barrera sociocultural para el establecimiento permanente en el punto de destino. 
La situación transitoria de los inmigrantes en los puntos de destino fortalece la idea del circuito. La circulación constante expande las referencias comunitarias en diversos sitios y momentos del circuito migratorio, reduciendo los tiempos y las distancias de los intercambios simbólicos entre comunidades locales y las de destino, construyendo, así, la imagen de la comunidad transnacional sobre las fronteras.

\section{VIDA Y ORGANIZACIÓN \\ COMUNITARIA TRANSNACIONAL}

La comunidad mixteca poblana transnacional se fortalece en dos elementos principales: en el papel de la religiosidad popular mexicana y en el de la organización comunitaria primordial, la cual descansa sobre el parentesco. Ambos elementos constituyen la fortaleza organizativa de las comunidades mixtecas inmigrantes en Estados Unidos, particularmente en la ciudad de Nueva York. Una red de organizaciones de derechos humanos, de origen jesuita, ha conjuntado estos elementos (religiosidad popular y organización comunitaria) en una asociación civil que se ha convertido en una típica organización transnacional: Asociación Tepeyac de New York, en cuyo nombre mismo expresa sincretismo cultural e identidad.

Asociación Tepeyac organiza e informa a los inmigrantes mexicanos en la ciudad de Nueva York acerca de derechos y recursos para hacer valer sus derechos. Su trabajo está dirigido, fundamentalmente, a inmigrantes indocumentados, pero atiende, en general, a todos los que solicitan sus servicios. Existe una alta proporción de poblanos organizados en Tepeyac. Esta organización fortalece el circuito transnacional, abriendo y ensanchando los canales para la circulación de bienes simbólicos, tales como las imágenes de las comunidades a través de la recreación de festividades, celebraciones, rituales, kermeses y fiestas de santos patrones, tal y como las realizan en las comunidades de la mixteca poblana. Estas celebraciones posibilitan la conexión local-global con las comunidades de origen y los diversos puntos del circuito (Rivera-Sánchez, 2001, 2002).

La remembranza constituye una estrategia básica de la organización para fortalecer la memoria colectiva, la fuente principal de la formación de la identidad, pero tal identidad -migrante mixteco-poblano-, en Nueva York, sólo puede ser recreada en la lógica del circuito migratorio transnacional. Un ejemplo de la remembranza a través del ritual lo muestra el padre Marcos en este relato:

Yo fui durante varios años a la celebración de Santiago Apóstol [en Nueva York], durante agosto, visitaba a la gente de mi pueblo (Chila de la Sal), organizábamos la fiesta como se hace allá. Un comité [se refiere a un comité guadalupano de Asociación Tepeyac] nos recibía y conseguía la parroquia [...] nosotros llevábamos todo desde acá. Los muchachos estaban contentos de poder ver sus cosas y sus comidas en la celebración. Iban hasta los que acá nunca se paraban por la iglesia. Sus mamás les enviaban cosas, que las estampitas y las virgencitas, al grado que muchos de ellos tenían sus altarcitos en sus departamentos, como sus mamás los tienen acá en la comunidad y acá [ellos] eran rejegos (padre Marcos, agosto de 2002).

De tal suerte, los comités guadalupanos, como grupos de base de la Asociación 
Tepeyac, están trabajando en los barrios de Nueva York como formas de nuevas relaciones socioespaciales para los inmigrantes mixtecos, a través de la reconstrucción de sus comunidades de origen en los barrios de Nueva York. Así, la dimensión local adopta un nuevo contenido simbólico en los barrios de la ciudad. Si bien, estos mixtecos están organizados de manera tradicional, como en sus comunidades locales, es decir, alrededor de parroquias y celebraciones de santos patrones, así como el reconocimiento de la Virgen de Guadalupe como patrona principal, ellos están también aprendiendo y enriqueciendo sus repertorios culturales en la interacción cotidiana de los barrios, con otros grupos nacionales, enfrentando nuevos problemas en los mercados de trabajo y en los lugares donde habitan. Estas formas de organización comunitaria, los rituales y las celebraciones, a pesar de ser organizadas a semejanza de las propias, ya no son las mismas, pues han sido incluidos los repertorios culturales, enriquecidos por los constantes encuentros pero, al tiempo, han sido reforzados por el sentido de pertenencia a una comunidad étnica fuera del territorio y como parte de una organización social también desterritorializada.

Los canales del circuito son estimulados por la organización comunitaria: un boletín informativo, llamado El Popocatépetl, transmite noticias de las comunidades migrantes, pero también de la comunidad local, que se funde en una sola comunidad al momento de la circularidad. Del mismo modo, un programa radial semanal y una página de internet fortalecen la circulación y colocan una nueva agenda en la vida migrante. Esta doble realidad, fundida en el circuito, está presente en el proyecto de visibilidad pública de la Asociación Tepeyac y la identidad del migrante, realidad que los mixtecos expresan muy bien: «el estar aquí y ser de allá, pero vivir en los dos al mismo tiempo».

El funcionamiento del circuito migratorio mixteca-Nueva York-mixteca está intrínsecamente ligado a la constitución de redes de migrantes que, desde el momento de su salida, establecieron contactos en los lugares de destino. Estas redes de migrantes en su dimensión regional, como transnacional, están ancladas en diversos puntos del territorio mexicano, pero también estadounidense; entre otros, hemos visto que están incluidos algunos otros puntos urbanos en México, los cuales sin duda forman parte también del circuito migratorio de estas comunidades. Algunos puntos identificados de este circuito están localizados en el Estado de México, particularmente nos referimos a Ciudad Nezahualcóyotl, Ecatepec y el Valle de Chalco. De tal forma, la red social sobre la que descansa el circuito se complejiza al conectar distintos puntos geográficos y enlazar redes de formación temporal diversa, indudablemente también permite vincular a migrantes de diferentes generaciones en un mismo proceso migratorio e, incluso, dentro de un mismo circuito.

La formación de estas redes ha posibilitado la creación de una infraestructura migrante que permite la recepción de personas del circuito, quienes arriban por primera vez a los puntos de destino en busca de trabajo. La red está basada en relaciones primordiales o apela a la identidad local común, facilitando información sobre empleos disponibles, recomendaciones para trabajar en un mismo restaurante, por ejemplo, conseguir vivienda y, quizá, recibir en préstamo un poco de dinero o alimentación mientras el nuevo inmigrante cobra su primer sueldo (Rivera-Sánchez et al., 2003).

Las redes se establecen en base a principios de solidaridad y pueden institucionalizarse en equipos deportivos, clubes de oriundos, grupos devocionales o reconstruir redes de parentesco a la manera de nuevas familias extensas en los barrios de Nueva York. La creación de nichos laborales para los mexicanos, en los mercados de 
trabajo de Nueva York, responde a la lógica de estas redes solidarias (Smith, 1997). De esta manera, los mexicanos mixtecos se ubican, fundamentalmente, en las cocinas de restaurantes griegos y coreanos, después en las cocinas de muchos otros restaurantes, aunque, indudablemente, ahora se han diversificado en otras actividades, las cuales hemos apuntado en la primera parte de este documento.

\section{CONCLUSIONES PRELIMINARES}

A lo largo de este escrito hemos observado las características de la migración mixteca poblana, sus diversas etapas y modalidades. Hemos realizado un recorrido a través de las variantes de la migración regional hacia centros urbanos y rurales de atracción de mano de obra, así como ilustrado los primeros momentos de la migración internacional. En un primer apartado hemos, asimismo, analizado las características sociodemográficas de los inmigrantes en la ciudad de Nueva York, lo que nos permitió, más tarde, destacar las transformaciones comunitarias que han experimentado los pueblos de la mixteca poblana en las diversas fases de migración, de la misma forma que observar cuáles son las transformaciones, en la fisonomía de las localidades, a partir del aceleramiento de la migración hacia Estados Unidos, ocurrida en las últimas dos décadas. Simultáneamente, este recorrido nos ha permitido entender los patrones de migración de los mixtecos, las modalidades de su establecimiento en Nueva York y la ausencia de barrios mexicanos.

Las transformaciones comunitarias se aprecian, no sólo en los cambios poblacionales y el paisaje local, sino en los estilos de vida, la modificación de los roles sociales, la relación entre hombres y mujeres y entre generaciones, en suma, las transformaciones se observan en las estructuras de la organización comunitaria, finalmente, en la constitución de identidades migrantes, producto de la conformación de un circuito migratorio dinámico de alta movilidad y con características particulares de organización comunitaria, que trasciende el ámbito local y se extiende a través de la frontera en una suerte de alargamiento socioespacial de la comunidad.

La consolidación del circuito migratorio mixteca-Nueva York-mixteca ha permitido la presencia de una comunidad mixteca transnacional, cuya dinámica se sostiene en el constante ir y venir de personas, dinero y bienes simbólicos en general. Esta investigación ha sugerido que el sustrato básico que consolida al circuito en su dimensión transnacional deviene no sólo de las remesas económicas, que sin duda impactan en las comunidades de origen, sino de las remesas socioculturales que posibilitan el fortalecimiento de la memoria colectiva en los diversos puntos del circuito, consolidan los vínculos primordiales y actualizan la pertenencia comunitaria, luego contribuyen en la consolidación de una identidad migrante que comparten tanto los que se van como los que se quedan o los que constantemente circulan por las redes del circuito. Esta identidad migrante se funda en repertorios culturales, producto del intercambio simbólico dinámico de imágenes, narraciones, discursos (lo que hemos llamado aquí remesas socioculturales); de tal suerte que la identidad migrante se encuentra desterritorializada y se reconstruye constantemente en el espacio transnacional.

Finalmente, la dinámica del circuito transnacional de los migrantes mixtecos ha generado diferentes formas de establecimiento en la ciudad de Nueva York, recreando espacios de identificación comunitaria, los cuales se diferencian de los barrios étnicos 
de otros grupos nacionales establecidos en la ciudad. La búsqueda de espacios comunitarios para inmigrantes de reciente arribo ha conducido a la generación de diversas formas de apropiación del espacio social en la gran urbe, basados, indudablemente, en el caso de los mixtecos poblanos y en las modalidades de organización propias de sus comunidades de origen.

\section{REFERENCIAS}

Abalos, T. (1986), Latinos in the United States. The Sacred and the Political, University of Notre Dame Press, Notre Dame.

Anderson, Benedict (1983), Imagined Communities, Verso Ed., London.

BAILEY, Thomas and R. Waldinger (1991), «Primary, secondary and Enclave Labor Markets: A training System Approach», en American Sociological Review, núm. $56,432-445$.

BASCH, Linda, Nina Glick Schiller y Cristina Szancton Blanc (1994), Nations Unbound: Transnational Projects, Postcolonial Predicaments and Deterritiorialized Nation-States, Gordon and Breach Ed.

Bean, F. y M. Tienda (1987), The Hispanic Population of the United States, Russell Sage Foundation, New York.

Gans, Herbert J. (1979), «Symbolic Ethnicity: The Future of Ethnic Groups and Cultures in America», en Ethnic and Racial Studies 2, núm. 1, 1-20.

(1997), «Toward a Reconciliation of 〈Assimilation〉 and 〈Pluralism〉: the interplay of Acculturation and Ethnic Retention», en International Migration Review, núm. 31, 75-92.

Glazer, N. (1997), We are Multiculturalists Now, Harvard University Press, Boston.

Goldring, Luin (1992), «Diversity in Transnational Migration», en Ph. D. dissertation, Cornell University.

González, Manuel G. (1999), Mexicanos. A History of Mexicans in the United States, Indiana University Press, Bloomington.

Gordon, M. (1964), Assimilation in American Life: the Role of Race, Religion and National Origins, Oxford University Press.

Gutiérrez, David (ed.) (1996), Between Two Worlds. Mexican Immigrants in the United States, Jaguar Books, Delaware.

Massey, Douglas (1987), «Understanding Mexican Migration to The United States», en American Journal of Sociology, vol. 92, núm. 6, 1372-1403.

, Luin Goldring y J. Durand (1994), «Continuities in Transnational Migration: An Analysis of Nineteen Mexican Communities», en American Journal Of Sociology, vol. 99, núm. 6, 1492-1533.

y K. Espinosa (1997), «What's Driving Mexico-U.S. Migration? A Theoretical, Empirical and Policy Analysis», en American Journal of Sociology, vol. 102, núm. 4, 939-999.

Piore, M. (1979), Birds of Passage. Migrant Labor and Industrial Societies, Cambridge University Press, New York.

Portes, Alejandro (1997), «Immigration Theory for New Century: Some Problems and Opportunities», en International Migration Review, núm. 31, 799-825. 
(1996), «Trasnational Communities: Their Emergence and Significance in the Contemporary Wordl-system», en R.P. Korzeniewidcz and W.C. Smith (eds.), Latin America in the World Economy, Greenwood, Westport, Conn. and R. Basch (1985), Latin Journey: Cuban and Mexican Immigrants in the United States, University of California Press, Berkeley. and L. Guarnizo (1991), «Capitalistas del Trópico: la inmigración en los Estados Unidos y el desarrollo de la pequeña empresa en la Republica Dominicana», en Comission for the study of International Migration and Cooperative Economic development, Washington, D.C.

and R. Manning (1986), «The Immigrant Enclave: Theory and Empirical Examples», en Susan Olzak and Joane Nagel (eds.), Competitive Ethnic Relatio$n s$, Academic Press, New York.

and Min Zhou (1992), «Gaining the Upper Hand: Economic Mobility Among Immigrant and Domestic Minorities», en Ethnic and Racial Studies, octubre. and Min Zhou (1993), «The Second Generation: Segmented Assimilation and its variants», en Annals of the American Academy of Political and Social Science, núm. 530, noviembre, Sage Publications, Philadelphia. and R. Rumbaut (1996), Immigrant America. A Portrait, University of California Press, Berkeley.

Richmond, Anthony (1988), Immigration and Ethnic Conflict, St. Martin's Press, New York.

Rivera Sánchez, Liliana (2001), «Pertenencias, identidades y espacios: construyendo una comunidad mexicana en Nueva York. El caso de Asociación Tepeyac», en Belén Lorente (ed.), El hecho religioso y la ayuda social. Estudios sobre su historia, epistemología y práctica, Corporación colombiana de investigaciones humanísticas-Humanizar, Bogotá. et al. (2003), Nuevos actores de la política social: las redes migrantes transnacionales, Instituto Nacional de Desarrollo Social, México.

Romanucci-Ross L., y G. De Vos (1995), Ethnic Identity: Creation, Conflict and Accomodation, Sage.

Rouse, Roger (1996), «Mexican Migration and the Social Space of Postmodernism», en David Gutierrez (ed.), Between Two Worlds. Mexican Immigrants in the United States, Jaguar Books, Delaware.

Sassen, Saskia (1991), Global City, Princeton University Press, Princeton.

Smith, Robert (1992), «New York in Mixteca; Mixteca in New York», en Report on the Americas, vol. xxvi, núm. 1.

(1996), «Mexicans in New York: Membership and Incorporation in a New Immigrant Community», en G. Haspil-Viera y S. Baver (eds.), Latinos in New York, Communities in Transition, University of Notre Dame Press, Notre Dame.

(1997), «Racial and Ethnic Hierarchies and the Incorporation of Mexicans in New York City: Transnational Communities and Labor Market Niches», en Draft Paper for Conference on Transnational Communities and the Political economy of New York City in the 1990's.

Waldinger, Roger (1986), Through the Eye of the Needle: Immigrants and Enterprise in New York's Garment Trade, New York University Press, New York.

(1990), «Korean, Hispanics and White Ethnic Employers in New York», unpublished manuscript. 
(1996), Still the Promised City? African-Americans and New Immigrants in Post-industrial New York, Harvard University Press, Cambridge.

Warner, Stephen and J. Wittner (eds.) (1998), Gatherings in Diaspora: Religious Communities and the New Immigration, Temple University Press, Philadelphia.

WARnER, Stephen (1999), «New Immigrant Religion: An Update and Appraisal», en Paper for Conference in New School for Social Research, octubre 12, 1999, unpublished manuscript.

WATERS, Mary C. (1994), «Ethnic and Racial Identities of Second Generation Black Immigrants in New York City», en International Migration Review, vol. 28.

WILson, Kenneth and A. Portes (1980), «Immigrant Enclaves: An Analysis of the Labor Market Experience of Cubans in Miami», en American Journal of Sociology, núm. 86.

YAng, Fenggang (1999), Chinese Christian in America: Conversion, Assimilation and Adhesive Identities, University Park, Penn State University Press.

ZHou, Min and Carl L. Bankston (1998), Growing Up American: How Vitnamese Children Adapt to Life in the United States, Russell Sage Publication, New York. 